\title{
A PRESERVAÇÃO CULTURAL SOB A ÓTICA DO IMAGINÁRIO E DA MEMÓRIA COLETIVA
}

Jeniffer Cuty ${ }^{1}$

\section{Observando a preservação através da cultura}

A idéia de pensar, refletir, planejar e compreender os espaços vividos está presente nas preocupações daqueles que atuam na (ou pela) cidade, sobretudo urbanistas, preservacionistas das arquiteturas e dos conjuntos urbanos, historiadores, arqueólogos e antropólogos. Entretanto, essa noção ganha nova delimitação semântica se nos detivermos na observação realizada por etnógrafos sobre cotidianos narrados por seus habitantes, através de suas formas de viver a cidade. Nessa maneira de pesquisar, as antropólogas do ambiente urbano, Ana Luiza Carvalho da Rocha e Cornelia Eckert, reconhecem etnógrafos e citadinos como uma “comunidade dialógica no âmbito de um campo semântico” (Eckert \& Rocha, 2008), ou seja, no contexto da cidade onde vivem e pesquisam. Assim, o pesquisador em campo, conforme o método trabalhado pelas autoras, encontra-se igualmente interessado em agenciar a interlocução com o habitante-narrador de suas experiências na cidade, bem como em se auto-observar e se descobrir nessa relação, resultando, por fim, numa produção intelectual única e movente, no sentido de se transformar ao longo do processo de pesquisa e, mais ainda, de interpretar uma cultura de sujeitos e grupos que narram e são narrados pela cidade. O método etnográfico aprimorado pelas teorias do imaginário e da memória coletiva revela-se, assim, primordial para o pensar e o fazer urbano.

O tradicional distanciamento do pesquisador da urbe em relação ao corpus de pesquisa, provocado pelas teorias e pelos métodos quantitativos, fazendo com que sua escrita seja obrigatoriamente higienizada do eu, aqui não se mantém. Essa forma de escrever e interpretar-se na cidade, proposta pela etnografia e aplicada na investigação antropológica da "cidade moderno-contemporânea”, conforme conceito de Gilberto Velho (2006), representa uma mudança significativa na experiência urbana e humana do pesquisador oriundo do campo das ciências sociais aplicadas, especialmente do Planejamento Urbano e Regional, área que se formou a partir de uma base interdisciplinar compreendida pelo urbanismo, pela geografia, pela economia, pela história e pelas ciências sociais, sobretudo a sociologia e as ciências políticas. Dois notórios pesquisadores de planejamento urbano dedicaram-se ao estudo da antropologia ao longo de suas carreiras, sendo eles o urbanista norte-americano Kevin Lynch (1918-1984) e o arquiteto brasileiro Carlos Nelson dos Santos, falecido na década de 1990. Ambos apresentaram obras de crescente complexidade, destacando-se em Lynch A Imagem da Cidade (1960), na qual

\footnotetext{
${ }^{1}$ Universidade Federal do Rio Grande do Sul, Brasil.
} 
o autor elabora as noções de legibilidade e imaginabilidade; What time is this place? (1972), obra em que o autor debruça-se sobre a reflexão do tempo nas transformações urbanas, que, para Lynch, desdobra-se em sentido e processo, fugindo do determinismo da física clássica; e, o mais trabalhado nos bancos acadêmicos de urbanismo, The Theory of Good City Form (1981), com recente tradução para o português intitulado A Boa Forma da Cidade (2006), seu último livro publicado em vida o qual traz a formulação de grandes categorias analíticas que pretendem dar conta do rendimento da forma urbana, em diferentes dimensões. O tempo e a construção da noção de ambiente foram preocupações constantes de Lynch, e, com certeza, esta abordagem merece relevo na compreensão da cidade contemporânea.

No caso da pesquisa antropológica sobre imaginário e memória coletiva, foco deste texto, a observação da cidade na sua materialidade, em seus equipamentos urbanos, por exemplo, se dá pela mão ou pela voz de seus habitantes, ou nos leva a eles, tendo em vista que o espaço se justifica e se representa no modo como ele é visto, sentido, criado e recriado por seus usuários na figura de narradores. Conforme assinalam as antropólogas Eckert \& Rocha:

(...) não são as representações sobre a cidade em suas lógicas e feitos externos que o habitante racionaliza, mas a interpretação que faz de sua própria experiência de sujeito da memória que o inscreve num mundo amalgamado de sistemas práticos e sistemas simbólicos (Eckert \& Rocha, 2008).

Sendo assim, identificamos outra ruptura na maneira de pensar o espaço urbano, considerado, por muitos autores, soberano e detentor do tempo nas suas feições, na suas fachadas e estruturas físicas, quando se referem a imóveis deteriorados ou em ruínas. Na visão da antropologia urbana proposta por Eckert \& Rocha, as ruínas são muito mais que apenas o resultado do abandono, elas são "gesto do esquecimento” (2007) e para entendê-las é preciso pensar na sua inserção na cidade. Orientadas pela leitura de Georg Simmel, Maurice Halbwachs, Gaston Bachelard e Gilbert Durand, as autoras nos ensinam a perceber que o tempo não está ali expresso nas paredes descascadas e mofadas, nos compartimentos desconfigurados, mas no “espaço fantástico” (Durand, 2002) da memória daqueles que habitam ou habitaram esse lugar. Como as ruínas protagonizam os debates sobre preservação de bens culturais, cabe discorrer, mesmo que brevemente, sobre elas, neste preâmbulo, no contexto das políticas culturais conservadoras ou inovadoras em vigor nas cidades brasileiras, em contraponto com a visão aproximada sobre um tempo descontínuo e a instabilidade estética (e ética) própria do mundo moderno.

Se tomarmos a teoria das formas de Georg Simmel, sobretudo de tragédia da cultura, estaremos considerando que algumas medidas de preservação fixam e deterioram lugares de referência cultural, por conta da impossibilidade de transformação desses espaços e da 
sobredeterminação de uma cultura objetiva sobre a cultura subjetiva. É preciso aceitar que algumas formas da cidade, diante das relações sociais e das práticas de interação carregam o sentido que as eternizam no tempo, enquanto outras se deterioram. É possível aproximar aqui a crítica feita pelo sociólogo francês Henri-Pierre Jeudy sobre a chamada preservação da memória em centros históricos. Argumenta Jeudy que isso é uma "imposição à memória coletiva, uma tirania” (1990), um caminho da monumentalização, a qual transforma as cidades em museus. Jeudy refere-se a uma “captura museográfica das culturas” e diferencia patrimônio de memória. Para o autor, “patrimônio é um modo de gerir a memória” (Jeudy, 1990), ao passo que a memória pode sobreviver sem uma concepção impositiva patrimonial. O autor destaca como positiva as intervenções contemporâneas que ocorrem em prédios antigos, por exemplo, aquelas feitas em Berlim e Londres. Interpreta ainda que o princípio patrimonial é um princípio terapêutico, sobretudo em tempos de angústia coletiva diante das transformações urbanas e ambientais.

As autoras Eckert \& Rocha recorrem ainda à obra de Georg Simmel para tratarem da memória vivida pelos habitantes na cidade. Salientam que

(...) no jogar o social, como diria Georg Simmel para definir a sociedade, importa situar o esforço da produção de sentido que relacione o indivíduo à coletividade, que situe o urbano no social, que mapeie as ações de sujeitos na cidade a valores éticos, em que embasam seus projetos de vida e formas de interagir no mundo social” (Eckert \& Rocha, 2008).

Cabe ainda questionar, subliminarmente ao longo da análise, onde está o referido valor cultural de bens protegidos ou inventariados para preservação. Para tanto seria relevante interrogar sobre a forma, no sentido simmeliano, como os consumidores e os produtores da cidade, seguindo denominação de Roncayolo (1980) se reconhecem, ou seja, se relacionam diante do chamado patrimônio cultural compreendendo que o espaço público ou privado, monumental ou vernacular, compõe a cidade de muitos tempos vividos e narrados, a cidade de muitos sentidos, assim como as construções populares comumente feitas pelas próprias mãos de seus moradores, os espaços de convívio nas praças, nos parques, institucionalmente constituídos ou não, os pequenos prédios residenciais da arquitetura proto-modernista com seus revestimentos em mica e seus modestos adornos, não tão destacados na paisagem como os monumentos ecléticos ou os neoclássicos, no entanto, em pleno uso e forte expressão nas capitais brasileiras, como Porto Alegre, São Paulo e Belo Horizonte, por exemplo. Vale, enfim, predispor-se a interpretar a cidade, na sua complexidade, riqueza e mesmo nas sombras cotidianas, assim como o cientista deve empreender a superar os obstáculos epistemológicos que se mostram no “âmago do próprio ato de conhecer”, como nos fala Gastón Bachelard (1996). Para o pesquisador urbano, 
habituado a olhar a cidade pela cancha de cima, num macro-zoneamento de questões e motivações retiradas do palco urbano e social, aceder ao método etnográfico e às teorias antropológicas do imaginário e da memória coletiva é “rejuvenescer espiritualmente, é aceitar uma brusca mutação que contradiz o passado”, parafraseando o mestre Bachelard, nas suas acepções sobre a formação do espírito científico.

\section{A cidade como espaço humanizado que comunica cultura e identidade}

No primeiro artigo aqui analisado de Eckert \& Rocha, "A cidade e suas crises, o patrimônio pelo viés da memória: porque e como preservar o passado?" (2006), as autoras problematizam a questão do patrimônio através da memória, demonstrando como a pesquisa antropológica possibilita interpretar os sentidos dos lugares urbanos e do pertencimento do público nos territórios da vida social. No segundo texto, intitulado "A cidade: Sede de sentidos" (2007), as autoras propõem a reflexão sobre políticas culturais que contemplem a visão acerca dos gestos de fundação da cidade e ampliem a noção de bem cultural nos termos de um patrimônio etnológico e não apenas histórico, artístico e arquitetônico. As autoras tomam como mote reflexivo o tombamento, em nível estadual, de edificações no campus central da Universidade Federal do Rio Grande do Sul, em Porto Alegre, para discorrer sobre as histórias narradas pelas gentes que ali passaram, pela pluralidade de espíritos que estetizam uma paisagem de pertencimentos, afetivos e conflitivos.

Em ambos os textos estudados para este ensaio, as antropólogas Eckert \& Rocha estão dedicadas a observar a cidade como fenômeno, no sentido adotado pelos autores da Escola de Chicago que, segundo elas, foram os primeiros a se interessarem pela desestruturação das megalópoles decorrente da concentração de grandes massas humanas. Na perspectiva de observação das dinâmicas sociais de destruição e de transformação presentes na chamada cidade moderno-contemporânea, afirma-se a necessidade de refletir a memória de grupos humanos que configuram a cidade e, mais ainda, do que é por elas denominado como "jogos da memória" (Eckert \& Rocha, 2005:101), ou seja, os atos de lembrar e esquecer que constroem, criam e recriam personagens e lugares. Em "A cidade e suas crises, o patrimônio pelo viés da memória: porque e como preservar o passado?" (2006), as autoras nos propõem pensar a questão do patrimônio e das formas de preservação a partir da compreensão de uma cidade que forma e é formada por seus habitantes, portanto existe uma necessidade de mútua compreensão tanto da cidade - que abriga lugares, personagens e ações, muitas vezes de crise e violência - quanto dos seus próprios habitantes. Elas grifam que 
(...) se somos a cidade, a cidade é nosso contexto. (...) Entende-se essa mensagem de diferentes formas, como um sistema comunicativo. Não reagimos a ela apenas psicologicamente (sem negligenciarmos aqui esse aspecto), mas comunicativamente, cultural, social e historicamente (Eckert \& Rocha, 2006).

Com isso, Eckert \& Rocha atingem um ponto central nesta reflexão urbana, buscando compreender que todos os espaços da cidade, institucionais, habitacionais, destinados ao lazer ou ao trabalho, abertos ou privados, carregam a pré-disposição para serem considerados de relevância cultural, entendendo que o que está em jogo nesse reconhecimento são "as formas de vida social no meio urbano, (...) as multiplicidades e as singularidades que encerram o vivido humano no interior desse espaço existencial criado pelo homem da civilização” (Eckert \& Rocha, 2008). Para um estudo mais aprofundado sobre o tempo e o espaço vivido, cabe aqui uma menção à obra Ciência do Homem e Tradição, de Gilbert Durand, dedicada a ilustrar, como diz o autor, “as transmutações de valores epistêmicos” (2008) sobre o homem, entre eles o chamado Homem Ocidental (da civilização ocidental) e a figura do Homem Tradicional, ou seja, aquele que opera sobre o mundo através de um pensamento simbólico. Nesta obra, o autor defende inicialmente a tese de que o

\begin{abstract}
(...) sentido da imagem do homem - o que faz com que a imagem do homem seja um símbolo que remeta a um significado vivido - só se recupera realmente se separarmos a imagem das "metamorfoses", ou seja, dos desvios que tiveram a ambição de "forçar" o sentido simbólico para substituí-lo pela dissecação não vivida dos conceitos, das definições claras e distintas, das extensas correntes da razão (Durand, 2008:13).
\end{abstract}

Para essa demonstração, Durand escolhe o Ocidente, tendo como propósito restituir a figura do homem tradicional através da interpretação da ciência. O autor refere-se a uma duração mais longa do mundo e do homem tradicional que aquela proferida pela História ou pela Paleontologia. Para ele, os historicismos são mitos produzidos pelo homem e que não produzem o homem. Nesse sentido, esta reflexão sobre homem e ciência está em pleno acordo com o modo como Eckert \& Rocha aderem a referentes teóricos e tensionam essas as suas preocupações de pesquisa sobre e no mundo urbano contemporâneo. Essa obra de Durand nos possibilita ainda encontrar importantes pistas sobre como refletir sobre o pensamento simbólico, aquele que conhece várias camadas de durações e várias regiões, e que, para o autor, é gnóstico, diferentemente do pensamento científico, agnóstico, ou seja, que acredita apenas no que vê. O pensamento simbólico procura o "sentido" e o que o domina em seu processo é a pluralidade qualitativa. Sobre a experiência espacial, Durand assinala que "um espaço pensado é substituído, pelo homem tradicional, por um ‘espaço vivido’ (...). Vivido quer dizer constituído pela vida e não apenas depois preenchido pela vida” (Durand, 2008:47), o que caracterizaria um espaço experimentado. Encontramos essa noção de sentido e de vivido, e da concepção simbólica do tempo, como aquele que permite, "simultaneamente, a reintegração do passado e a adivinhação 
ou profecia do futuro” (Durand, 2008:49), internalizada na obra sobre a memória coletiva, as formas de sociabilidade e os itinerários urbanos das antropólogas Eckert \& Rocha. Esses conceitos são trabalhados, pelas autoras, a partir da observação da cultura no social, das formas de viver e de narrar (os tempos vividos) o urbano, para, assim, atualizar conceitos do método por elas denominado “etnografia da duração” (2005) e sob a perspectiva do estudo da "cidade como objeto temporal” (2005) apoiada em uma “idéia de Tempo coletivo enraizado no território urbano a partir de gestos, práticas, dramas de seus habitantes (...) espelhando referenciais culturais de um passado coletivo” (Eckert \& Rocha, 2005:87).

A conceituação de tempo coletivo e de espaço humanizado nos encaminha para a leitura do segundo texto “A cidade: Sede de sentidos” (2007), em que a abordagem etnográfica sobre bens patrimoniais tangíveis e intangíveis perpassa igualmente pela complexa reflexão das dinâmicas sociais de destruição e transformação a partir do olhar sobre um determinado território na cidade de Porto Alegre, mais especificamente o campus central da Universidade Federal da UFRGS, o qual abriga bens imóveis tombados em nível estadual. Logo no primeiro parágrafo do artigo, as autoras provocam seus leitores a refletir o patrimônio tombado a partir da teoria das formas, da tragédia da cultura e de uma reconciliação entre cultura objetiva e cultura subjetiva retiradas da obra de Simmel, bem como da noção de trajeto antropológico, de Gilbert Durand. Devemos, portanto, nos deter a este último conceito, tendo em vista que ele está igualmente presente em toda a obra de Eckert \& Rocha sobre a cidade, o mundo contemporâneo e o tempo. Em sua densa produção intelectual sobre o homem, os mitos e as imagens, Durand nos contempla com um estudo sobre “As estruturas antropológicas do imaginário” (2002), por ele apresentada como um repertório das grandes constelações imaginárias. Neste livro, o autor destaca que o Imaginário "aparece-nos como o grande denominador fundamental onde se vêm encontrar todas as criações do pensamento humano" (Durand, 2002:18). Com o foco centrado nos estudos sobre o simbolismo imaginário, Durand mergulha na antropologia, conjunto de ciências que estudam o homo sapiens, e propõe que a investigação situe-se no que ele chama “trajeto antropológico", por ele definido como “a incessante troca que existe ao nível do imaginário entre as pulsões subjetivas e assimiladoras e as intimações objetivas que emanam do meio cósmico social” (Durand, 2002:41). Esta posição, segundo o autor, afasta os problemas de anterioridade ontológica à pesquisa, tendo em vista que ele postula, definitivamente, que "há gênese recíproca que oscila do gesto pulsional ao meio material e social e vice-versa” (Durand, 2002:41). Com isso, o autor afirma que o imaginário nada mais é que esse trajeto e que o símbolo, entendido como o próprio trajeto, "é sempre o produto dos imperativos biopsíquicos pelas intimações do meio” (Durand, 2002:41). Sendo assim, é plenamente coerente realizarmos 
reflexões sobre bens culturais, dotados de carga simbólica e referenciados ao gesto que o compõe e que é decorrente da ação e da imaginação criadora do homem sobre o mundo, igualmente interagindo sobre ele, a partir da obra durandiana. Durand escreve que o "trajeto é reversível, porque o meio elementar é revelador da atitude adotada diante da dureza, da fluidez ou da queimadura. (...) o trajeto antropológico pode indistintamente partir da cultura ou do natural psicológico" (Durand, 2002:41-42).

No estudo da cidade como espaço de ação da memória individual e coletiva, a qual “adere às motivações simbólicas de diferentes civilizações que modelam os arranjos espaciais” (Eckert \& Rocha, 2007:350), nos deparamos com um princípio de compreensão de configurações urbanas e humanas que identifica traços comuns em tempos e espaços distintos. Desse modo, reforça-se a necessidade de iluminarmos valores éticos e morais, interpretarmos lembranças históricas no centro da civilização ocidental, para compreendermos nossa cidade e nossos bens patrimonializados. Se nos valermos da compreensão de trajeto antropológico, poderemos pensar a cidade que se preserva, desvendando os chamados "mitos de fundação das comunidades urbanas do Ocidente, reunindo lendas, crenças, saberes, fazeres, histórias, tradições... e utopias” (Eckert \& Rocha, 2007:346). Para isso, devemos nos deter em territóriosmito, como o próprio campus da universidade enquanto lugar habitado por histórias, para identificar, no nosso amplo objeto de estudo que é a cidade, um patrimônio etnológico, ou seja, “que tenha por base as heterodoxias do passado, salvaguardando o essencial de uma memória coletiva urbana, segundo a multiplicidade de seus suportes e a imensa vitalidade silenciosa de seus símbolos” (Eckert \& Rocha, 2007:354).

Como estamos nos referindo ao trabalho de memória coletiva e de preservação cultural, citamos, como exemplo, o recente trabalho de observação de detalhes de bens culturais imóveis, tombados no Centro de Porto Alegre e restaurados, entre 2002 e 2008, pelo Programa Monumenta $^{2}$, que foram traduzidos em obras artesanais, no intuito de resgatar imagens ou remeter a elas aqueles que convivem com estes detalhes cotidianamente e não se apercebem deles e aqueles que as visitam eventualmente ou uma única vez, como turistas estrangeiros. Nessa relação que se estabelece entre objetos artesanais, carregados de intenção simbólica de referenciar e homenagear o patrimônio tombado/restaurado, dedicados à contemplação e seus

\footnotetext{
${ }^{2}$ O Programa Monumenta/BID figura como o principal programa de preservação da cultura urbana e arquitetônica brasileira, atualmente em vigor em 26 cidades de porte pequeno, médio e grande. Instituído no final de 1999 pelo Ministério da Cultura, em cooperação com o Banco Interamericano de Desenvolvimento - BID, com apoio técnico da UNESCO e parceria da Caixa Econômica Federal, o Programa Monumenta, foi calcado na experiência de Quito. A capital do Equador, em 1988, sofreu um abalo sísmico que danificou gravemente os monumentos do seu Centro Histórico, já inscrito na época, como Patrimônio da Humanidade. O retorno considerado positivo a partir das ações de restauração e dinamização cultural de Quito, promovidas pela instituição de um Fundo com recursos do BID, levou o Banco, em 1995, a propor ao Ministério da Cultura do Brasil um Programa similar, voltado às principais cidades históricas do país e implantado pelas administrações municipais.
} 
fruidores, apreciadores, conhecedores, destacamos uma ação de memória, portanto temporal e inteligente sobre os objetos, os bens que os inspiraram e a própria cidade que os produz.

Gilbert Durand nos fala sobre a função fantástica que guia todo o espectro de criação do espírito humano, tanto teórico quanto prático. Para o autor, essa função é universal e está “na raiz de todos os processos de consciência” (Durand, 2002:397). Tendo em vista que a consciência imaginante, como nos ensina Durand, está no movimento do pensamento que não separa o subjetivo do objetivo, ela é, portanto, transcendente, ou seja, vai além das coisas e dos sujeitos. Essa consciência é fundamental no sentido de imaginar (e preservar) o mundo, ou seja, de criá-lo num espaço de memória, transcendente e fantástico.

Cabe observar na obra de Durand que, antes de refletir o espaço, no caso da memória, dedica-se longamente a pensar o tempo, através da observação dos mitos e da leitura crítica de autores como Sartre, Jung, Bergson, Bachelard e outros. O tempo nos encaminha para a degradação e a morte, ao passo que no domínio da fantástica (pura, o sonho e transcendental, a memória) observamos um lento processo temporal que ocorre num espaço com qualidades a serem conhecidas. "A memória, longe de ser intuição do tempo, escapa-lhe no triunfo de um tempo reencontrado, logo negado” (Durand, 2002:401). A memória organiza esteticamente a recordação, daí o seu caráter fundamental do imaginário que é ser eufemismo, tendo em vista que ela ergue-se contra o tempo e "assegura ao ser (...) a continuidade e a possibilidade de regressar, para além das necessidades do destino” (Durand, 2002:403). Com essa capacidade de “redobramento de instantes”, a memória dá “espessura inusitada ao monótono e fatal escoamento do devir” e, conseqüentemente, ela ocorre num espaço igualmente denominado fantástico, que difere do espaço euclidiano, aquele considerado por Kant como a forma a priori da experiência. Se a memória, que é experiência sobre o mundo, ocorre num espaço não físico e objetivo, o qual apresenta características como a ocularidade, a profundidade e a ubiqüidade, descritas por Durand como qualidades desse espaço, podemos inferir que sua manifestação humana assume tanto a função de eufemismo e de esperança, quanto de principal criação e preservação no sentido de delegar valor ao mundo e à cidade que nos cerca e nos compõe.

Ambos textos lidos e analisados para este ensaio contemplam esses conceitos durandianos nas suas reflexões originais e vão além da simples leitura teórica, pois trazem a interpretação a partir de etnografias e, mais ainda, a partir de um método proposto pelas autoras, Eckert \& Rocha, para estudar a cidade contemporânea, a etnografia da duração (2005). Para compreender este método é necessário entender os conceitos de duração e de memória, adotados pelas autoras a partir da interpretação de Bachelard e Durand, especialmente, e aplicados ao estudo da cidade contemporânea. Esse método "vislumbra o tratamento da memória como 
conhecimento de si e do mundo” (Eckert \& Rocha, 2005:154). Tomando por foco o estudo das narrativas dos habitantes da cidade, a etnografia da duração persegue essas recordações e compreende que as imagens narradas e recordadas engendram sentidos e são, elas, decorrentes de uma associação de idéias. Logo, essa memória configura-se como ação inteligente de interiorização do fluxo temporal, tornando suas operações reversíveis e caracterizando-se como um ato de duração.

\section{Ainda sobre o tempo e o espaço: o Homem na cidade}

Durand nos ensina que "os transbordamentos do reducionismo condenavam as ciências humanas a perder o homem pelo caminho, a trocá-lo pelos projetos vazios dos formalismos ou pela falta de sentido da explicação causal” (Durand, 1993). Eckert \& Rocha, nas suas pesquisas e nos seus escritos, levam em consideração essa assertiva, no sentido de não reduzir a leitura do homem e da cidade, mantendo suas múltiplas nuanças interpretativas e, acima de tudo, observando sempre a presença da imaginação criadora nos gestos humanos.

Talvez a maior referência à obra de Gilbert Durand na extensa produção das antropólogas Ana Luiza Carvalho da Rocha e Cornelia Eckert esteja na forma de construir o pensamento sobre o mundo, sobre a cidade pensada, vivida, humanizada. Se tudo o que ocorre na cidade é produto da ação humana, então, para compreendê-la é necessário interpretar, na complexidade e na riqueza cotidiana, seus moradores, consumidores e produtores, ou seja, manter as sutilezas de suas narrativas no próprio texto científico e no pensamento que o encerra. Se a cidade é produto da ação e da memória coletiva, a expressão cunhada por Kara-José (2007) como intervenções urbano-culturais, referindo-se a ações decorrentes da intenção de preservar alterando cuidadosamente feições e funções urbanas ou construir observando valores culturais, é redundante, pois é no urbano, sobretudo no social, que se dá a cultura. A noção de ambiente urbano é aquela que compreende a multiplicidade de formas sociais que dele se apropriam, ou não, para reconhecerem e darem sentido a eles, grifando, cotidianamente, sua relevância cultural.

\section{Referências}

BACHELARD, Gaston. A dialética da duração. São Paulo: Ática, 1988.

BACHELARD, Gaston. A formação do espírito científico: constribuição para uma psicanálise do conhecimento. Rio de Janeiro: Contraponto, 1996.

BENJAMIN, Walter. Charles Baudelaire um lírico no auge do capitalismo. Obras escolhidas volume III. São Paulo: Ed. Brasiliense, 1989.

CHOAY, Françoise. A alegoria do patrimônio. São Paulo: Ed. Unesp, 2001.

DURAND, Gilbert. A imaginação simbólica. Lisboa: Edições 70, 1993.

DURAND, Gilbert. As estruturas antropológicas do imaginário: introdução à arquetipologia geral. São Paulo: Martins Fontes, 2002.

DURAND, Gilbert. Ciência do Homem e Tradição: o novo espírito antropológico. São Paulo: 
Triom, 2008.

ECKERT, Cornelia e ROCHA, Ana Luiza Carvalho da. O tempo e a cidade. Porto Alegre: Editora da UFRGS, 2005.

ECKERT, Cornelia \& ROCHA, Ana Luiza Carvalho da. A cidade e suas crises, o patrimônio pelo viés da memória: porque e como preservar o passado. In: Habitus, Revista do Instituto de Pré-História e Antropologia. Universidade Católica de Goiânia. Goiânia, GO, Ed. da UCG. Vol. 1, n. 1, jan./jul. 2006.

ECKERT, Cornelia \& ROCHA, Ana Luiza Carvalho da. A cidade: Sede de sentidos. In: LIMA FILHO, Manuel Ferreira, ECKERT, Cornelia, BELTRÃO \& Jane Felipe (org.). Antropologia e patrimônio cultural: diálogos e desafios contemporâneos. ABA. Blumenau: Nova Letra, 2007. pp. 343-361.

ECKERT, Cornelia e ROCHA, Ana Luiza Carvalho da. Narrar a cidade: experiências de etnografias da duração. In: POSSAMAI, Zita (org). Leituras da Cidade: Porto Alegre e seu patrimônio. Porto Alegre, Editora da UFRGS, no prelo. (mimeogr, 2008).

JEUDY, Henri-Pierre. Memórias do social. Rio de Janeiro: Forense Universitária, 1990.

KARA-JOSÉ, Beatriz. Políticas culturais e negócios urbanos: a instrumentalização da cultura na revitalização do Centro de São Paulo (1975-2000). São Paulo: Annablume, Fapesp, 2007.

LYNCH, Kevin. What time is this place? Cambridge: MIT Press, 1972.

LYNCH, Kevin. A imagem da cidade. São Paulo: Martins Fontes, 1997.

RICOEUR, Paul. Arquitetura e Narratividade. Urbanisme, Paris: n. 303, p. 44-51, nov./dez. 1998.

RONCAYOLO, Marcel. La ville et ses territoires. Paris: Gallimard, 1980.

SIMMEL, Georg. Questões fundamentais da sociologia. Rio de Janeiro: Jorge Zahar, 2006.

SOUZA FILHO, Carlos Frederico Marés de. Bens culturais e proteção jurídica. Porto Alegre: UE/Porto Alegre, 1997.

VELHO, Gilberto. Antropologia urbana: cultura e sociedade no Brasil e em Portugal. Rio de Janeiro: Jorge Zahar Ed., 2006. 